\title{
Lung Cancer with Rare Occurrence of Distal Appendicular Skeletal Metastases
}

\author{
Kishor Taori, Ajinky Patil*, Lalit Garg, Ramesh Parate, Priya Tembhare, Rohini Rathod, \\ Jawhar Rathod, Amit Disawal, Anand Hatgaonkar
}

Department of Radiodiagnosis, Government Medical College, Nagpur, India

Email: ${ }^{*}$ ajinky gmc@yahoo.co.in

Received 2 April 2014; revised 12 May 2014; accepted 6 July 2014

Copyright (C) 2014 by authors and OALib.

This work is licensed under the Creative Commons Attribution International License (CC BY).

http://creativecommons.org/licenses/by/4.0/

C. (i) Open Access

\begin{abstract}
Distal appendicular skeletal involvement is a rare finding. Skeletal metastases by far is ranked 3 rd in place after liver \& brain. Among the skeleton, axial skeleton has a predilection. We report a 65-year-old male with lung cancer with distal ulnar metastases. Patient has swelling of left wrist from last 6 months. Physical examination revealed ill-defined, painful, swelling of left wrist joint. Radiograph revealed permeative destruction of distal ulna. On examination infectious/neoplastic etiology was considered but on evaluation the primary was found to be lung malignancy with distal ulnar metastases.
\end{abstract}

Keywords

Lung Cancer, Distal Appendicular Skeletal Metastases

Subject Areas: Oncology, Pathology, Radiology \& Medical Imaging

\section{Introduction}

Metastasis to distal part of appendicular skeleton is not so often finding. Lung malignancy and renal cell carcinoma are two notorious malignancies known to present in such a way. We present a 65-year male patient with distal ulnar metastases which on evaluation was found to be harboring Lung cancer. But it is not very frequently found. Patient presents with swelling \& pain involving distal appendicular skeleton which is generally viewed as infective or non-neoplastic in origin. This delays diagnosis and treatment. Here we describe a case of distal appendicular skeletal metastases with the primary being Lung cancer.

\section{Case Report}

A 65-year-old male patient came to outpatient department as swelling and pain in left wrist joint since 6 months. "Corresponding author.

How to cite this paper: Taori, K., Patil, A., Garg, L., Parate, R., Tembhare, P., Rathod, R., Rathod, J., Disawal, A. and Hatgaonkar, A. (2014) Lung Cancer with Rare Occurrence of Distal Appendicular Skeletal Metastases. Open Access Library Journal, 1: e738. http://dx.doi.org/10.4236/oalib.1100738 
No history of trauma or fever was present. No significant past or family history was present. Patient was a chronic smoker and alcoholic (H/o smoking for last 40 years). Physical examination revealed ill-defined, painful, left wrist joint swelling with restriction of joint movement. Plain radiograph left wrist joint (Figure 1(a)) showed permeative/moth eaten destruction involving distal 1/3rd part of left ulna with breach in cortex at multiple places with associated surrounding soft tissue swelling.

On computed tomography, wrist revealed lytic destruction involving distal part of left ulna with surrounding soft tissue swelling (Figure 1(b)). Infective/neoplastic was kept as provisional diagnosis. But he had no h/o fever. Thus infection was ruled out. There was no associated expansion of affected bone or periosteal reaction or significant soft tissue mass, and the length of involvement was $<6 \mathrm{~cm}$. Thus it significantly ruled out primary involvement of bone. Eventually secondary involvement was suspected.

Cytological examination of left wrist joint (Figure 1(c)) revealed findings of Squamous cell carcinoma. But the primary was unknown. Thus we looked for primary as renal cell carcinoma by USG abdomen which revealed no significant abnormality. Since the patient was a chronic smoker we then suspected of lung malignancy. Hence, chest radiograph was done which showed a well defined, large right parahilar radio-opaque lesion (Figure 1(d)). To confirm the nature of the lesion contrast enhanced CT thorax was done which revealed large,

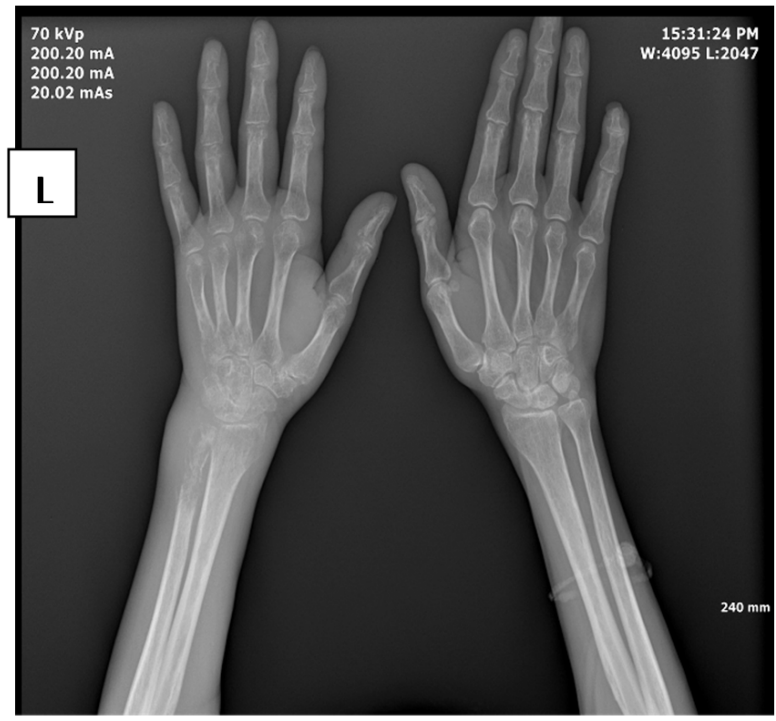

(a)

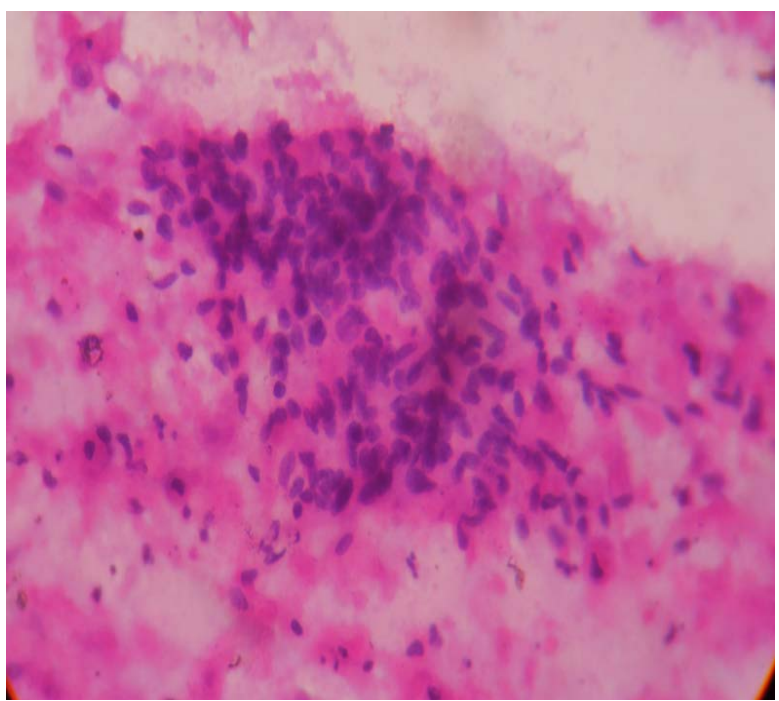

(c)

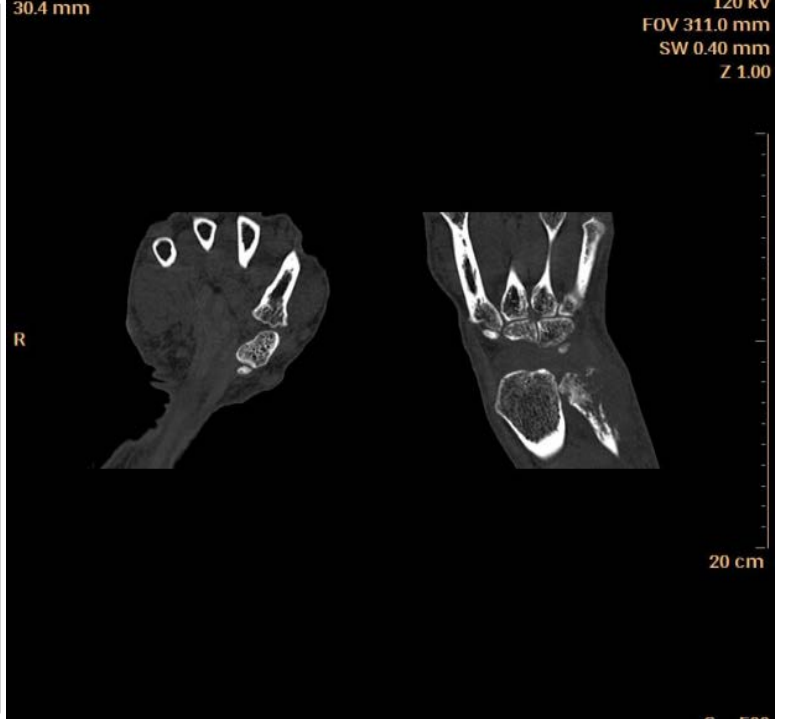

(b)

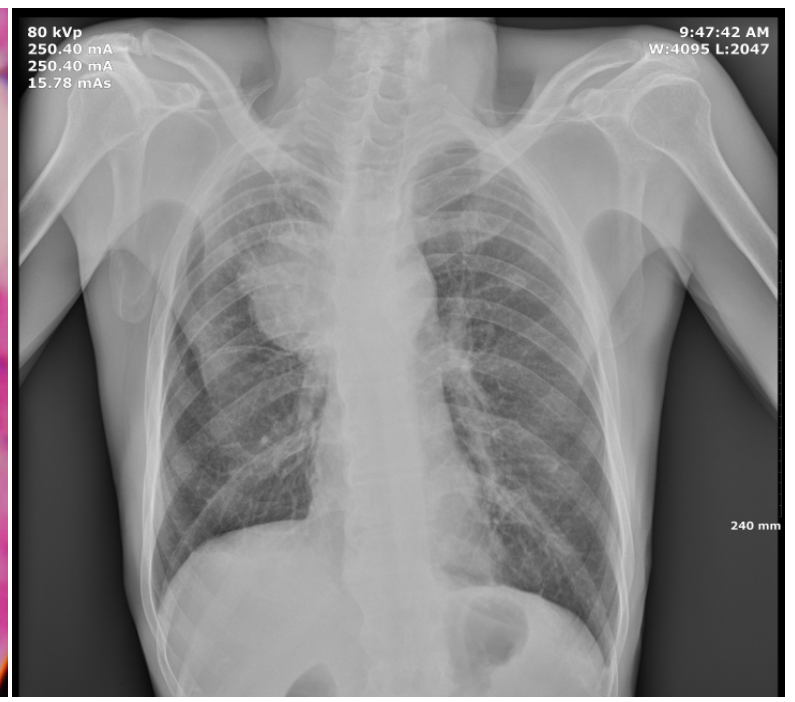

(d) 


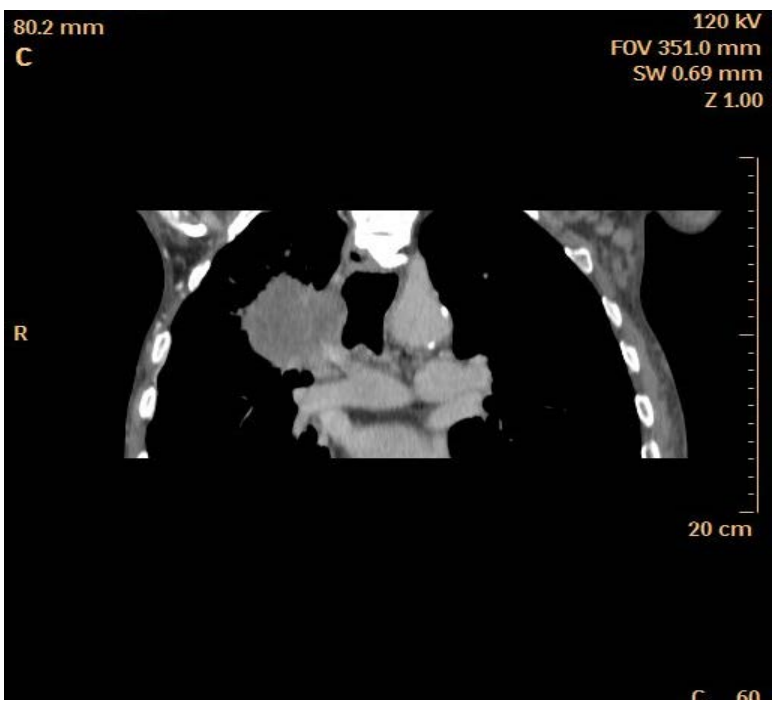

(e)

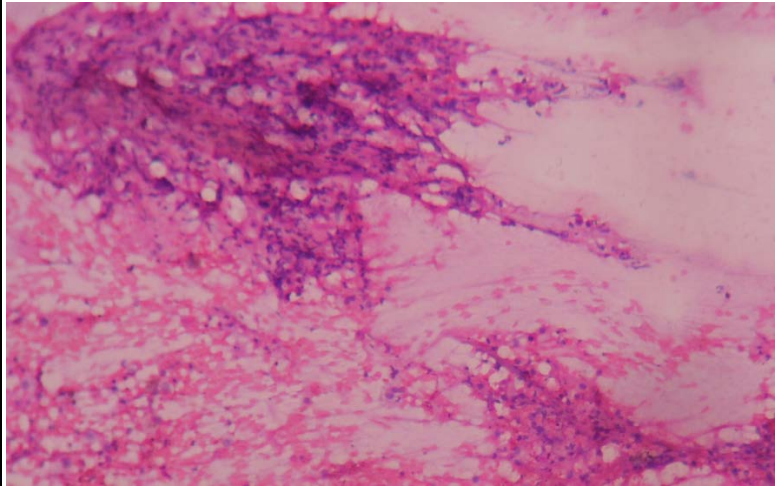

(f)

Figure 1. (a) Showing permeative/moth eaten destruction involving distal 1/3rd part of left ulna with breach in continuity at places; (b) Showed lytic destruction involving distal part of left ulna with fracture \& surrounding soft tissue swelling; (c) FNAC from left wrist lesion: smear showing scattered cells with flat moderate amount of cytoplasm with keratinisation \& hyper chromatic pyknotic nuclei suggestive of metastases of squamous cell carcinoma; (d) A well-defined, large right parahilar radio-opaque lesion without any air bronchograms within; (e) Large, well-defined, nodular, heterogeneously mildly enhancing, hypo dense lesion in right parahilar location with spiculated margins; (f) FNAC from right parasternal mass: smear shows scattered squamous cells with pleomorphism; hyper chromatic nuclei with scattered pigment laden macrophages, inflammatory cells \& few sheets of reactive mesothelial cells s/o squamous cell carcinoma.

well-defined, nodular, heterogeneously mildly enhancing, hypo dense lesion in right parahilar location with spiculated margins suggestive of possibly lung malignancy (Figure 1(e)). This was confirmed on cytological examination as Squamous cell carcinoma (Figure 1(f)).

Thus retrospective evaluation of left distal ulnar bone's destructive lesion concluded with eventual finding of primary malignancy in right lung.

Patient was registered under radiotherapy department and was undergoing chemo radiotherapy (30 grays in 10 fractions). However, patient died after 3 months.

\section{Discussion}

Skeletal metastases frequently affect axial skeleton \& proximal appendicular skeleton. Metastatic lesions of bone beyond elbows \& knees rarely occur [1]. Lung \& kidney malignancies are notorious for causing such metastases while breast \& gastrointestinal malignancy are other causes [2]. The tumor cells migrate to distal site by hematogeneous route and not via lymphatic route [3]. While the spread of tumor involving multiple visceral organs is halted due to hepatic \& pulmonary capillary bed, lung cancer cells gain unresisted access to distal arterial system. This explains the occurrence of distal skeletal metastases with lung cancer more commonly [3].

The occurrence of lung cancer with distal appendicular skeletal involvement is rare and occult primary with such presentation is still very exceptional. One of the study showed that about $10 \%$ of such cases become symptomatic before the primary would manifest [4]. The presentation of metastases to bones would vary. The affected part may appear infected. It may appear inflamed, erythematous, tender, swollen [5]. Metastases of bronchogenic carcinoma usually appear lytic [2]. In our case initially infective \& neoplastic (primary/secondary) was kept as differentials. But cytological examination helped us reached the proper diagnosis.

Regarding the treatment part, it is palliative. In the literature, it has been mentioned that local radiotherapy would help alleviate pain and swelling locally [2].

\section{Conclusion}

Though metastases distal to elbow \& knee joint is rare phenomenon, considering it as one of the strong differen- 
tial of destructive lesion of distal appendicular skeleton against infective and evaluating in a respective way would help the physician to detect the malignancy early. As this case showed, clinicians should be watchful in screening patients those at risk of developing lung cancer and are having persistent distal appendicular skeletal complaints.

\section{References}

[1] Greenfield G.B. (1980) Radiology of Bone Diseases. 3rd Edition, JB Lippincott, Philadelphia.

[2] Flynn, C.J., Danjoux, C. and Danjoux, C. (2008) Two Cases of Acrometastasis to the Hands and Review of the Literature. Current Oncology, 15, 51-58.

[3] Asencio, G., Hafdi, C.H., Pujol, H. and Allieu, Y. (1982) Osseous Metastases in the Hand. A General Review of Three Cases. Annales de Chirurgie de la Main, 1, 137-145. http://dx.doi.org/10.1016/S0753-9053(82)80069-0

[4] Baran, R., Guillot, P. and Tosti, A. (1998) Metastasis from Carcinoma of the Bronchus to the Distal Aspect of Two Digits. British Journal of Dermatology, 138, 708. http://dx.doi.org/10.1046/j.1365-2133.1998.02193.x

[5] Khokhar, N. and Lee, J.D. (1983) Phalangeal Metastasis: First Clinical Sign of Bronchogenic Carcinoma. Southern Medical Journal, 76, 927. http://dx.doi.org/10.1097/00007611-198307000-00031 